\title{
Autism Spectrum Disorder and the Use of Virtual Reality Technologies to Address Core Social Communication Deficits-A Statement of Position
}

\author{
Ian T Miller ${ }^{1 *}$, Catherine S Miller ${ }^{2}$, Mark D Wiederhold ${ }^{3}$ and Brenda K Wiederhold ${ }^{1,3}$ \\ ${ }^{1}$ Interactive Media Institute, USA \\ ${ }^{2}$ Speech Tree Therapy Center, USA \\ ${ }^{3}$ Virtual Reality Medical Center, USA
}

Submission: February 13, 2019; Published: February 26, 2019

*Corresponding author: Ian T Miller, Interactive Media Institute, San Diego, California, USA

\begin{abstract}
Autism Spectrum Disorder (ASD) is a neurodevelopmental condition that manifests core deficits in social communication and interaction, alongside restrictive, repetitive patterns of behaviors, interests, and activities (RRBIs). behaviors are recognized as maladaptive forms of communication. Moreover, current frameworks identify these behaviors and other areas of core deficit as impairments in predictive abilities. Because individuals along the spectrum have difficulty with Theory of Mind (ToM) and Executive Function (EF), their ability to parse out salient contextual information and disambiguate environments is impaired. This is particularly evident in social situations. Past research points to the utility of communication-based interventions to help individuals learn to navigate dynamic social environments by teaching functional communication strategies (i.e. communicating basic wants and needs).
\end{abstract}

As a result, individuals are better able to communicate their needs, thereby decreasing the occurrence of RBBI. Although current intervention techniques (i.e. Carol Gray's social stories) are effective at teaching functional communication, there is a growing need for more accessible and usable intervention tools for clinicians, families, caregivers, and autistic individuals themselves. The current work presents the use of virtual reality (VR) to address these needs and mobilize ASD services to those most in need. Validated across myriad clinical populations and implemented specifically for ASD interventions, VR is a unique platform that presents lifelike simulations of the real world on a moments' notice. Emerging research on the applicability and efficacy of VR in ASD is presented, followed by a brief discussion of the literature and direction of future research.

Keywords: Neurodevelopmental; Maladaptive; Predictive; Symptomatology; Contextual

Abbreviations: ASD: Autism Spectrum Disorder; SLP: Speech-Language Pathologists: VR: Virtual Reality: TD: Typically Developing: IMI: Interactive Media Institute; ToM: Theory of Mind; EF: Executive Function

\section{Introduction}

Autism Spectrum Disorder (ASD) is a neurodevelopmental condition that manifests core deficits in social communication and interaction, alongside restrictive, repetitive patterns of behaviors, interests, and activities [1]. ASD symptomatology is expressed variably-and to varying degrees-in the 1 in 59 affected persons in the United States [2]. Researchers associate many of the fundamental symptoms of ASD with inaccuracies in processing and predicting dynamic environments-a predictive impairment [3-5]. Sinah et al. [3] explain predictive impairment as an inaccuracy in deciding which contextual information is most important.

The advantage of discriminating which sensory inputs matter most helps individuals process and categorize information into schemas, using them to probabilistically infer future events. However, probabilistic thinking is inaccurate when contextual discrimination is inhibited [3] and since decoding dynamic environments requires accurate schemas and probabilistic thinking, when this ability is hindered, as in ASD, processing and functioning in dynamic environments is inefficient and overwhelming $[3,4]$. Thus, even "A world that seems at least somewhat predictable to typical people can strike those with autism as capricious" [6].

When an environment is unpredictable it elicits psychological responses such as stress and anxiety [7]. Research suggests these responses are catalysts of restrictive, repetitive patterns of behaviors, interests and activities characteristic of ASD [8]. Core 
deficits in social communication compound these responses because many individuals along the spectrum have difficulty telling peers, clinicians, caregivers or family members how they are feeling or thinking [9]. Up to $80 \%$ of these behaviors serve a communicative function [10-12], suggesting functional communication (i.e. communicating basic wants and needs) is integral to navigating dynamic environments.

In fact, the most recommended intervention methods by clinicians and the most sought-after service by families are those focused on teaching basic communication skills [8]. These interventions, often delivered by Speech-Language Pathologists (SLPs), utilize pictures, props, and toys to teach autistic individuals how to label the most contextually salient aspects of dynamic environments and identify the appropriate corresponding response or action. Functional communication helps autistic individuals learn to discriminate between necessary (salient) and unnecessary contextual information to form basic schemas on dynamic environments-ultimately leading to more meaningful interactions and more efficient navigation of social environments $[13,14]$.

While evidence supports the efficacy of communication interventions to improve social functioning, the transferability of these skills from the clinic to the real world is a major concern [15]. A disadvantage of clinical interventions is their lack of ecological validity; because interventions are not delivered in their natural context, the transfer of learned skills to the real world is hindered [16]. As such, there is a need to supplement evidence-based therapies for children and adolescents with tools that enhance skill generalization to and maintenance in the real world.

\section{Virtual reality in ASD interventions}

In recent years, virtual reality (VR) has been increasingly researched as a tool to address this drawback for its ability to immerse individuals in realistic environments on demand. When a user is "immersed" in VR, their objective measures, such as physiological monitoring, react as if in the physical setting (i.e. driving), while users subjectively report a sense of presencefeelings of "being there"-when experiencing VR. The sensation of presence is a unique characteristic of VR and points to the use of this technology for presenting social contexts and teaching social interaction and communication skills with autistic persons.

VR has been applied to teach concrete, procedural skills to intellectually disabled persons for over 15 years. Some of these applications include teaching fire safety [17], job interview skills $[18,19]$, and public transportation skills [20]. Until recently, realistic social interaction and communication were difficult to produce in VR. However, as our understanding of the capabilities of VR expanded and the hardware and software improved, researchers have been more able to explore the nuances of social skills and communication

\section{Discussion}

As evidenced in Table 1, VR can successfully be applied to assess and teach social communication skills in a variety of autistic populations. For example, various groups have explored the use of VR and related technologies in children. Measuring social skills with clinical observations, participant questionnaires and interviews, Ke and Im reported that their VRbased intervention improved participants' ability to greet peers, initiate conversation, respond to peers' cues in conversation, and appropriately end a conversation (i.e. saying goodbye, thank you, etc.) [21]. Research by Sarah Parsons corroborated these findings, highlighting not only that autistic individuals can learn to exhibit appropriate reciprocity in conversation, but that they can achieve similar rates of reciprocity as typically developing (TD) peers [22]. Didehbani et al. [23] revealed that robust intervention (10 1-hour sessions over a five-week period) can significantly improve many core features of social communication, such as emotion recognition, attention and executive function. Similar results are indicated in older autistic populations as well (Table 1) [24-27].

Table 1: Provides a brief overview of recent VR and autism intervention literature with a particular emphasis on social interaction and communication [21-27].

\begin{tabular}{|c|c|c|c|c|}
\hline Date & Authors & Topic & Conditions & Results \\
\hline \multicolumn{5}{|c|}{ Children (Ages 5-12) } \\
\hline 2013 & Ke F, et al. [21] & $\begin{array}{c}\text { VR based social interaction } \\
\text { training }\end{array}$ & $\begin{array}{l}\text { Children with high functioning ASD } \\
\text { participated in VR-based social } \\
\text { interaction tasks. Behavior observations, } \\
\text { questionnaires and interviews measured } \\
\text { the effect of VR on interaction and } \\
\text { communication performance. }\end{array}$ & $\begin{array}{l}\text { Participants improved performance } \\
\text { in responding, initiation, greeting, } \\
\text { and positive conversation-ending } \\
\text { during the intervention, and } \\
\text { improved social competence } \\
\text { measures after the intervention. }\end{array}$ \\
\hline 2015 & Parsons S [22] & $\begin{array}{l}\text { VR to enable the } \\
\text { reciprocal interactions } \\
\text { \& communicative } \\
\text { perspective-taking } \\
\text { between children. }\end{array}$ & $\begin{array}{c}\text { Measured interactional moves and } \\
\text { peer-peer communication in } 8 \text { typically } \\
\text { developing (TD) children and } 6 \text { with ASD in } \\
\text { a collaborative VR game. }\end{array}$ & $\begin{array}{c}\text { ASD \& TD groups exhibited } \\
\text { equal communicative reciprocity. } \\
\text { TD scored higher on sustained } \\
\text { endeavors to communicate. Pairs } \\
\text { of autistic individuals and TD } \\
\text { individuals communicate in the } \\
\text { collaborative VR game in similar } \\
\text { ways. }\end{array}$ \\
\hline
\end{tabular}




\section{Global Journal of Intellectual \& Developmental Disabilities}

\begin{tabular}{|c|c|c|c|c|}
\hline 2016 & $\begin{array}{l}\text { Didehbani N, et } \\
\text { al. [23] }\end{array}$ & $\begin{array}{l}\text { VR social cognition } \\
\text { training to enhance social } \\
\text { skills in children with ASD }\end{array}$ & $\begin{array}{l}30 \text { children participated in 10,1-hour } \\
\text { sessions over } 5 \text { weeks while researchers } \\
\text { measured emotion recognition, social } \\
\text { attribution, attention and executive } \\
\text { function. }\end{array}$ & $\begin{array}{l}\text { Results revealed improvement } \\
\text { across all measures and presents } \\
\text { support for VR as a platform to offer } \\
\text { effective social cognition training. }\end{array}$ \\
\hline 2018 & $\begin{array}{c}\text { Zhao H, et al. } \\
{[24]}\end{array}$ & $\begin{array}{l}\text { A communication- } \\
\text { enhancement collaborative } \\
\text { VR system for promoting } \\
\text { social interaction. }\end{array}$ & $\begin{array}{l}12 \text { children with ASD and } 12 \text { TD children } \\
\text { participated. Interactive VR games tasked } \\
\text { participants with collaboratively moving } \\
\text { virtual objects using gaze and voice-based } \\
\text { communication to communicate, share } \\
\text { information and discuss game strategy. }\end{array}$ & $\begin{array}{c}\text { Feasibility study results indicate } \\
\text { that the VR system was accepted } \\
\text { by both groups and improved } \\
\text { their game play cooperation. } \\
\text { There is potential for VR to foster } \\
\text { communication and collaboration } \\
\text { skills in children with ASD. }\end{array}$ \\
\hline \multicolumn{5}{|c|}{ Adolescents and Emerging Adults (Ages 13-24) } \\
\hline 2012 & $\begin{array}{c}\text { Kandalaft M, } \\
{[25]}\end{array}$ & $\begin{array}{l}\text { VR social cognition } \\
\text { training intervention to } \\
\text { enhance 1) social skills, } \\
\text { 2) social cognition and 3) } \\
\text { social functioning }\end{array}$ & $\begin{array}{l}8 \text { young adults (mean age } 21 \text { ) navigated VR } \\
\text { social environments like an office, coffee } \\
\text { shop, and park while encountering common } \\
\text { social interactions (i.e. office contained an } \\
\text { interview scenario). }\end{array}$ & $\begin{array}{l}\text { After } 10 \text { sessions of the } \\
\text { intervention, scores significantly } \\
\text { increased on some measures of } \\
\text { verbal and non-verbal recognition } \\
\text { and theory of mind. The results } \\
\text { indicate VR has promise as a } \\
\text { platform l to improve social } \\
\text { cognition. }\end{array}$ \\
\hline 2014 & $\begin{array}{l}\text { Wade J, et al. } \\
\text { [26] }\end{array}$ & $\begin{array}{l}\text { Eye-gaze tracking and } \\
\text { VR driving environment } \\
\text { to assess performance of } \\
\text { autistic teenagers. }\end{array}$ & $\begin{array}{l}4 \text { teens diagnosed with ASD and } 4 \text { TD teens } \\
\text { (mean age 16) completed a virtual driving } \\
\text { trial and were required to complete various } \\
\text { tasks. Researchers tracked eye movements } \\
\text { and successful task completion. }\end{array}$ & $\begin{array}{l}\text { ASD group exhibited significantly } \\
\text { higher task errors. Eye-gaze analysis } \\
\text { revealed a higher (vertical gaze) } \\
\text { in the ASD group and significantly } \\
\text { higher skin conductance measures, } \\
\text { indicating increased levels of } \\
\text { anxiety in the ASD group. }\end{array}$ \\
\hline 2015 & $\begin{array}{c}\text { Lahiri U, et al. } \\
\text { [27] }\end{array}$ & $\begin{array}{l}\text { Physiologically responsive } \\
\text { VR system to facilitate } \\
\text { conversation skills in } \\
\text { adolescents. }\end{array}$ & $\begin{array}{c}8 \text { (mean age } 15 \text { ) participants with } \\
\text { ASD participated in } 2 \text { VR-based social } \\
\text { interaction tasks with eye-gaze capturing, } \\
\text { physiological monitoring, and voice } \\
\text { recording }\end{array}$ & $\begin{array}{l}\text { Results from this small usability } \\
\text { study suggest that such } \\
\text { physiological responsive VR } \\
\text { avatars can be used to improve } \\
\text { communication skills. }\end{array}$ \\
\hline
\end{tabular}

The exciting potential of virtual reality and related technologies points to a future of research that incorporates both subjective clinical observations and questionnaires, as well as objective measures such as eye-gaze capturing and physiological monitoring to attain a holistic and robust understanding of the effects and use cases of VR for autistic populations. Lahiri et al. [27] reported the implementation of a physiologically responsive VR social cognition system for autistic adolescents, showcasing a method that detects physiological responses and adjusts in real-time to provide an individualizable and personalized treatment experience.

While research across clinical and nonclinical populations reports enhanced skill transfer and maintenance when using VR, a comprehensive review of the literature states that the application of VR in ASD-specific interventions is relatively nascent and most studies are not well controlled [28]. Table 1 highlights studies investigating the applicability and feasibility of VR in autistic populations, though robust clinical studies are absent. Didehbani et al. [23] had the largest sample size and most robust protocol, delivering VR-based social cognition training to 30 child participants over a 10 -session protocol, though the authors cite a "relatively small sample size" as the first limitation of the study.

Another limitation of current research is the lack of comparison of VR-based treatments to traditional treatments [28].
Though a few studies compare ASD groups to typically developing (TD) individuals $[22,24,26]$, comparative research between intervention groups is necessary. Thus, well-controlled between group comparisons of skill acquisition, generalization, and maintenance are an important next step in researching the feasibility and efficacy of VR interventions for children and adolescents along the autism spectrum.

\section{Conclusion}

ASD is a complex condition that manifests symptoms to widely variable degrees. The diversity of symptoms poses obstacles to effective, efficient and accessible intervention services. However, understanding ASD, in part, as a product of impairments in sensory discrimination and predictive ability open the door to numerous interesting VR intervention techniques for autistic individuals. For example, under this framework of predictive impairment [3], cooccurring restrictive or repetitive behaviors and interests may better be investigated as deficits in communication and adaptive interaction skills (i.e. learning to discriminate between important and un important environmental cues). Moreover, while immersing individuals in social contexts or presenting them with social interaction opportunities in VR, researchers can collect valuable physiological data that is otherwise difficult to collect in reallife scenarios. These physiological markers can help researchers 1) objectively measure participants' affective states in social 
VR, 2) investigate biomarkers of stress and anxiety and their relationship to ASD symptomatology, and 3) adapt environments in real-time, helping to individualize treatments and personalize the VR experience in a way that appropriately addresses the participant's needs.

Currently, Interactive Media Institute (IMI) and its affiliate, the Virtual Reality Medical Center (VRMC), are building on past research and moving toward the development of mobile interventions systems that can increase access to services for those most in need. From inexpensive mobile HMDs to other wearable technologies, there is potential to create more individualizable interventions for individuals with ASD and related conditions. In this effort, VRMC has recently established an Autism Center for Excellence that is dedicated to creating, testing, and disseminating effective and accessible interventions for individuals with ASD. VRMC is working with funders to continue developing its capabilities.

In all, VR is a promising supplemental healthcare technology that provides advantages to treatments that focus on real-world skill transference. In the treatment of ASD, social communication and interaction are the top treatment concern for parents and clinicians. Extant research supports the application of VR and related technologies to improve social cognition and basic communication strategies. Future research is needed to validate much of the current preliminary and exploratory research. Nonetheless, as society moves further into the digital age, and as younger generations expand their technological literacy, VR and related technological tools will be important in improving access, efficiency, and outcomes for a variety of populations.

\section{References}

1. Baio J, Wiggins L, Christensen DL, Maenner MJ, Daniels J, et al. (2018) Prevalence of autism spectrum disorder among children aged 8 yearsAutism and Developmental Disabilities Monitoring Network, 11 Sites, United States, 2014. MMWR Surveill Summ 67(6): 1-23.

2. Arlington VA (2013) American Psychiatric Association. Diagnostic and statistical manual of mental disorders. ( $5^{\text {th }}$ edn.), American Psychiatric Association.

3. Sinha P, Kjelgaard MM, Gandhi TK, Tsourides K, Cardinaux AL, et al. (2014) Autism as a disorder of prediction. Proc Natl Acad Sci USA 111(42): 15220-15225

4. Van de Cruys S, Evers K, Van der Hallen R, Van Eylen L, Boets B (2014) Precise minds in uncertain worlds: Predictive coding in autism. Psychological Rev 121(4): 649-675.

5. Haker H, Schneebeli M, Stephan KE (2016) Can Bayesian theories of autism spectrum disorder help improve clinical practice?. Frontiers Psychiatry 17(7): 107.

6. Musser G (2018) Does autism arise because the brain is continually surprised? Science Magazine.

7. Grillon C, Baas JP, Lissek S, Smith K, Milstein J (2004) Anxious responses to predictable and unpredictable aversive events. Behav Neurosci 118(5): 916-924.

8. Anixt JS, Meinzen-Derr J, Estridge H, Smith L, Brinkman WB (2018) Characteristics of treatment decisions to address challenging behaviors in children with autism spectrum disorder. J Dev Behav Pediatr 39(4): 282-291.
9. Wright J (2017) Unmasking Anxiety in Autism: Anxiety can assume unusual forms in people with autism-turning uncertainty, or even a striped couch, into a constant worry. New tools may help identify these hidden fears. Scientific American.

10. Prizant B, Wetherby A (2005) Critical Issues in enhancing communication abilitites for persons with autism spectrum disorder. Handbook of Autism and Pervasive Developmental Disorders. Hoboken, pp. 925-945.

11. Prizant BM, Wetherby AM (1987) Communicative intent: A framework for understanding social-communicative behavior in autism. Journal of the American Academy of Child \& Adolescent Psychiatry 26(4): 472479 .

12. Derby K, Wacker D, Sasso G, Steege M, Northup J, et al. (1992) Brief functional assessment techniques to evaluate aberrant behavior in an outpatient setting: a summary of 79 cases. J Appl Behav Anal 25(3): 713-721.

13. Kevin Lanning, Rachel E, Pauletti, Laura A King, Dan P McAdams (2018) Personality development through natural language. Nature: Human Behaviour 2: 327-334.

14. Watkins L, Kuhn M, Ledbetter-Cho K, Gevarter C, O Reilly M (2017) Evidence-based social communication interventions for children with autism spectrum disorder. Indian J Pediatr 84(1): 68-75.

15. DeRosier ME, Swick DC, Davis NO, McMillen JS, Matthews R (2011) The efficacy of a social skills group intervention for improving social behaviors in children with high functioning autism spectrum disorders. J Autism Dev Disord 41(8): 1033-1043.

16. Mancil GR (2006) Functional communication training: A review of the literature related to children with autism. Education and Training in Developmental Disabilities 41(3): 213-224.

17. Padgett LS, Strickland D, Coles CD (2005) Case study: Using a virtual reality computer game to teach fire safety skills to children diagnosed with fetal alcohol syndrome. J Pediatr Psychol 31(1): 65-70.

18. Smith MJ, Fleming MF, Wright MA, Losh M, Humm LB, et al. (2015) Brief report: Vocational outcomes for young adults with autism spectrum disorders at six months after virtual reality job interview training. J Autism Dev Disord 45(10): 3364-3369.

19. Smith MJ, Ginger EJ, Wright K, Wright MA, Taylor JL, et al. (2014) Virtual reality job interview training in adults with autism spectrum disorder. Journal of Autism and Developmental Disorders 44(10): 2450-2463.

20. Simões M, Bernardes M, Barros F, Castelo-Branco M (2018) Virtual Travel Training for Autism Spectrum Disorder: Proof-of-Concept Interventional Study. JMIR serious games 6(1): e5.

21. Ke F, Im T (2013) Virtual-reality-based social interaction training for children with high-functioning autism. The Journal of Educational Research 106(6): 441-461.

22. Parsons S (2015) Learning to work together: designing a multi-user virtual reality game for social collaboration and perspective-taking for children with autism. International Journal of Child-Computer Interaction 6(1): 28-38.

23. Didehbani N, Allen T, Kandalaft M, Krawczyk D, Chapman S (2016) Virtual reality social cognition training for children with high functioning autism. Computers in Human Behavior 62: 703-711.

24. Zhao H, Swanson AR, Weitlauf AS, Warren ZE, Sarkar N (2018) Handin-Hand: A Communication-Enhancement Collaborative Virtual Reality System for Promoting Social Interaction in Children With Autism Spectrum Disorders. IEEE Transactions on Human-Machine Systems 48(2): 136-148.

25. Kandalaft MR, Didehbani N, Krawczyk DC, Allen TT, Chapman SB (2013) Virtual reality social cognition training for young adults with high-functioning autism. Journal of autism and developmental disorders 43(1): 34-44. 
26. Wade J, Bian D, Zhang L, Swanson A, Sarkar M, et al. (2014) Design of a virtual reality driving environment to assess performance of teenagers with ASD. InInternational Conference on Universal Access in HumanComputer Interaction, pp. 466-474.

27. Lahiri U, Bekele E, Dohrmann E, Warren Z, Sarkar N (2015) A physiologically informed virtual reality based social communication system for individuals with autism. Journal of autism and developmental disorders 45(4): 919-931.
28. Mesa-Gresa P, Gil-Gómez H, Lozano-Quilis JA, Gil-Gómez JA (2018) Effectiveness of virtual reality for children and adolescents with autism spectrum disorder: an evidence-based systematic review. Sensors 18(8): 2486.

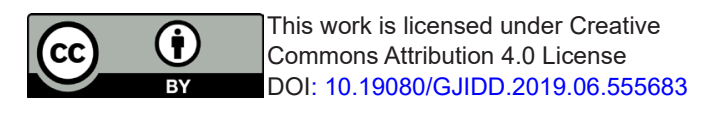

\section{Your next submission with Juniper Publishers will reach you the below assets}

- Quality Editorial service

- Swift Peer Review

- Reprints availability

- E-prints Service

- Manuscript Podcast for convenient understanding

- Global attainment for your research

- Manuscript accessibility in different formats ( Pdf, E-pub, Full Text, Audio)

- Unceasing customer service

Track the below URL for one-step submission https://juniperpublishers.com/online-submission.php 